\title{
The Surface Movements of the Earth's Crust. ${ }^{1}$
}

\author{
By Prof. J. Joly, F.R.S.
}

T HE land surface of the globe has been, for the most part, many times covered by the sea in the course of geological time. The mountain ranges of the earth, as now known, have only recently attained their present elevation; other mountain ranges formerly existed which have now been all but obliterated by the remorseless effects of denudation.

It is important that we should study for a little what happens when a great mountain range is developed on the surface of the globe. There is a long period of preparation for the stately event; a period many millions of years in duration. First, there are signs of unrest in the solid land of the continents. The sea rises on the coasts and transgresses on the wide lands within, very gradually stealing over the lower levels. This process may not be steady and continuous. There may be periods of retreat followed by periods of advance, but always the land, as a whole, goes on sinking deeper and deeper into the sea. Many millions of square miles may be covered with the shallow seasperhaps to a depth of two or more hundred fathomsso that a considerable portion of the land area of the globe may become sea before the downward movement ceases. This transgression is a slow process; so slow and long-enduring that, while the submergence lasts, great depths of sediment accumulate in the transgressional seas.

Then at length there comes a resurrection. The land begins to emerge; but not the old land which went down. Where the great accumulations of sediment had been, mountain ranges arise. In short, what arises from the ocean grave is a crushed and wrinkled world, shattered by faults and over-thrusts and exhibiting every evidence of great horizontal compression. One attendant of these events is the outbreak of volcanoes and floods of lava welling out of fissures in the earth's crust. The latter generally appear along western coasts, or to the west of the new-born mountain ranges.

These events draw to a close when the land has attained its former elevation, more or less. There is then a new era of geological history-a long era of organic progress, lasting many millions of years, during which minor oscillations of the crust and local deformation may occur. This is a period of active denudation. The last-born mountains are degraded by denudation, and their sediments collected into the great troughs or geosynclines, and the sublime but unreasoning sequence of events is repeated all over again.

Such has been in leisurely repetition the history of the earth. Certain world-revolutions are generally accepted-although geologists are not all agreed as to their number - as comprised in the period of 150 or 170 million years which the statistics of denudation and the record of thorium lead ascribe to the age of our era. Four or five world-revolutions appear to enter into that time interval. Thus 30 or more millions of years may, tentatively, be ascribed to the genesis and consummation of a world-revolution.

1 From a public lecture delivered under the auspices of the Royal Dublin Society on March 7.
From these broad features of geological history it is evident that some source of unrest, acting upon the surface of the earth, which periodically recuperates its strength, runs a course involving an enormous expenditure of energy, and then dies down into quietude, must exist. What can this source of unrest be ?

In the science of isostasy we are confronted with the strange fact (for fact it undoubtedly is), that the lands of the earth-firm as they may appear-are yet floating like rafts or pontoons on a yielding substance far beneath. Now, the continents are built of rocks, such as granite, gneiss, sandstone, etc., and in the same way as the sea-water must be denser than the icebergs which float upon it, so the substance which buoys up the continents must be denser than granite and chemically similar materials.

We get a very sure guidance as to the nature of the sustaining substance in a direct and simple way by paying attention to the nature of the lava which is poured out in enormous volumes on the surface of the land during times of revolution. This substance comes up as a thin and very fluent liquid. It may flow for 50 or 60 miles over the ground before congealing. It solidifies to a black and heavy solid---basalt.

There appears to be no doubt-and in this many petrologists are agreed-that basalt is the primary rock-magma upon which the continents float and which buoys up the great oceans of the earth. Just beneath continents and oceans it forms a layer over the whole earth--a layer to which isostasy ascribes a depth of some 60 to 70 miles. This substance, basalt, therefore, plays a very important part in the surface history and physical phenomena of the globe. Primarily, and most important of all, we know that it contains a small quantity of radio-active substances. No basalt ever examined failed to reveal this fact. These radio-active substances continually evolve heat. We know of no conditions which can check, or in any way alter or modify, this ceaseless evolution of thermal energy. Hence we must recognise that in every cubic centimetre of this great magmatic ocean upon which the continents and seas float there is a source of slow thermal evolution.

Keeping in mind that the central problem to be solved with respect to the great land movements affecting the surface of the globe is to account for the great outbreak of igneous activity and crustal disturbance all over the surface of the earth every 25 or $3 \circ$ million years, we naturally ask if the perennial supply of radio-active heat may not furnish the explanation.

The thermal properties of basalt under ordinary conditions have been fairly well examined. At a temperature of $\operatorname{II} 50^{\circ}$ it softens, at $1225^{\circ}$ it flows freely, forming a very mobile but heavy liquid. In passing from one state to the other there is a volume increase of about ro per cent. of the initial volume. This may be a rather excessive value. It is not less than 6 per cent.

Now, the fact that the basalt in these great floods reached the surface in a fluid state is adequate proof 
that it was at a high temperature in the regions deep down from which it came. This is its condition generally all the world over during times of revolution. There are many reasons for believing that at the present time it does not and cannot generally exist in the fluid state; although deep pockets of the fluid magma must probably exist at all times throughout the magma-ocean and beneath the continents, there extends for a very long period after a revolution a shallow layer of the melted rock. Generally throughout the deep isostatic layer it possesses the characters of a plastic solid and is yielding enough for the continents to float upon it. The addition of a certain known quantity of heat to each gram of the highly heated basalt will convert it to the liquid state.

We know, as the result of many experiments, the quantity of radio-active substances in basalt. Samples from various great lava flows and volcanoes have been examined. There are certain variations in the quantities observed from one great flow to another. Taking a mean we can calculate the quantity of heat which would be generated, say, in one million years in each gram of the basalt. Briefly stated, the results of our investigation show that the heat accumulated in about 25 million years would suffice to turn the solid basalt, nearly at its melting-point, into a liquid.

The first effect of this change will be a considerable expansion in volume and corresponding loss of density and buoyancy. For, as has been stated, the solid basalt near its melting-point expands some 6 to ro per cent. of its volume in changing to the liquid state. The result upon the continents is easily inferred. When a ship sails from the salt water of the ocean into a river of fresh water it sinks a little; so also the continents will sink a little. The waters of the ocean will therefore transgress upon the lands, advancing century after century as the basalt changes its state, as we know happens in periods preceding a revolution. Hence the earliest phase of geological change finds an explanation in the melting of the basalt which floats the continents.

But other consecutive consequences follow. For when, all over the earth, beneath continents and oceans, there extends a deep sea of melted lava, it is evident that conditions arise favourable to greatly increased volcanism both on the land and over the floor of the oceans.

The melted basalt will again lose heat and revert to the solid state. It may take 3 to 4 million years for this to happen, but happen it must. For liquids part with heat much more quickly than solids, just because circulation can go on in them. Now the basalt, where it laps against the rocky floor underlying the oceans, loses its heat far more rapidly than radio-activity can supply it. It probably melts away a good deal of the ocean floor in the process of parting with its heat. The ocean floor is very probably, almost certainly, also basalt. Possibly this floor becomes very thin indeed in the course of the long period during which the great ocean of lava is returning to the solid or plastic state.

It will be understood that the change of state has completely altered the conditions of heat-loss, the gain of heat per gram remaining the same at all times. The solid basalt can only lose heat by conductivity- a very slow process: Beneath the continents even this means of escape is almost closed, because the base of the continents possesses a high temperature, arising from the radio-active content of the continental materials themselves. Beneath the ocean, a few miles down, the conditions become much the same. Thus the solidified magma must conserve practically all its heat-gains. When fusion becomes general convection begins, as well as other movements later to be referred to. The escape of heat beneath the oceans becomes then relatively rapid.

But now notice the effect upon the continents of this reversion to the solid condition. When the basalt regains the solid state it also regains its original density ; and the land regains its original buoyancy. The continents must now rise again to their former altitude above the sea. They are as ships passing from the river to the ocean. The waters which flowed in upon the continents during the slow process of the melting of the basalt must recede again as the basalt resolidifies. Hence a final great phase of geologic change finds explanation in the physical properties of the basaltic ocean and its inevitable thermal changes.

We can only discuss with any degree of definiteness the events progressing in the upper region of the great basaltic ocean. For the depth of this ocean is probably not less than 60 miles, and the pressures prevailing in such depths greatly modify the behaviour of substances experiencing accession or loss of heat, but there is no reason to believe that any effects to which reference has been made will be seriously modified. On the contrary, the effects, so far as we can infer them, of great pressure in the depths appear to bring events still more into harmony with geological observations and inferences.

From what has been stated we see that the reason for the long time intervals between the epochs of worldwide revolution is to be found in the smallness of the quantity of radio-active substances existing in the great sustaining magma supporting the continents and the oceans. On an average, it takes some 25 millions of years for the change of state to be brought about attending which the continents must sink and the waters transgress upon their surface. Then some 3 to 5 millions of years may be required for the stored radio-active heat to be again dissipated. The cycle is therefore accomplished in, say, 30 millions of years. These figures are given merely as suggestive of what might prevail. Various causes, which cannot be discussed, may modify them.

We live at a period immediately succeeding a very great world-revolution. The lava ocean has lost its heat of fluidity for the most part, and the continents float upon the basalt sea as upon a plastic or viscous body nearly at its melting temperature. These conditions are really very wonderful; but the explanation of our immunity is simple. The melting-point of the continental rocks is from $200^{\circ}$ to $500^{\circ}$ higher than that of basalt. Again, solid rock conducts heat badly. Hence little or no heat reaches us from the fiery ocean beneath.

We have next to consider if we cannot find an explanation of mountain-building and volcanic phenomena as involved in the changes we have been discussing. We know that the ocean tides are due to lunar and

NO. 2792, VOL. I I I] 
solar gravitational attraction. Oceanic tides are comparatively feeble phenomena; for not only is the ocean shallow and obstructed by land, but also water is a fluid of low density. But during times of revolution, just beneath the continents and oceans, there comes into existence a vast and far deeper ocean, composed for a great part of a highly fluid substance having a density three times that of water. We seem to have, therefore, good and sufficient reason for expecting greatly intensified tidal phenomena to arise during these times. So also a precessional force must act with intensified effect in periods of revolution. Both these forces tend to retard the surface crust of the earth in its diurnal rotation from west to east; that is, they tend to hold it back a little from partaking of the general easterly rotation of the globe. The effect is greatest in equatorial regions.

Fig. I shows, to an exaggerated vertical scale, a

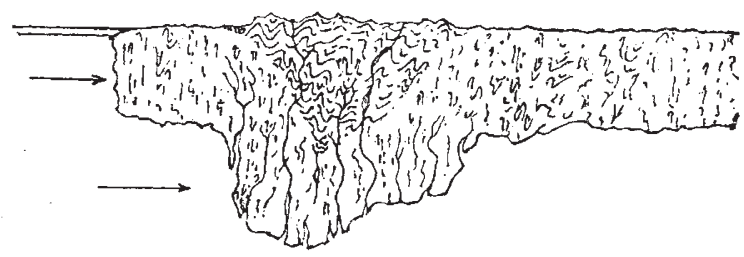

FIG. r.-Diagram of continental border-section W. to E.

portion of a continent seen in section, along with a part of a neighbouring ocean, both floating upon the basaltic magma. West is to left and east is to right. We must imagine that the lower, more viscous part of the magma possesses the full west-to-east angular velocity of the earth; but the continents and oceans and upper layers of the magma are, in virtue of the westerly forces just referred to, not moving quite so fast in that direction. They respond, in fact, to the forces urging them westward. We perceive that this involves, of necessity, an east-going force or pressure acting upon the submerged parts of the continents, and more especially upon the more deeply submerged parts ; that is, upon the displacements required by isostasy to float the greater raised features of the continents.

The diagram is intended to illustrate the effect of the magmatic pressure with reference to mountainbuilding. We have already seen that mountain ranges arise where great depths of sediment collect for long ages. These accumulations may amount to several miles in depth; the sediments pressing down the crust as they collect.

It is well known that this process creates a linear area of weakness in the floating continent. We can picture what happens. The great load bends down the crust, forcing it deep into the hot magma. It becomes seamed with gaping vents and cracks, extending parallel with the axis of the trough into which the magma forces itself.

Now, if a horizontal force acts upon a continent affected with such an area of weakness, this part yields first and the sediments are crushed and forced both upwards and downwards. The part that rises up forms the mountain range; the part that is thrust downwards acts as compensation or buoyancy, which serves to float the mountain. The one adjusts itself to the other. The mountains slowly sink or rise till there is equilibrium. Thus, in course of ages, we get the floating mountain range. It will be perceived that the volume of the downward displacement is much greater than the mountain range. This is because the density of the crust does not differ greatly from that of the sustaining magma.

Such great ranges as the Cordilleras of North and South America rose up out of troughs of sediments in this manner. They were specially favourably oriented to receive the easterly pressure of the underlying magma, and, correspondingly, they are in many respects the greatest mountain developments of the globe.

However, while it seems easy to understand that the formation of mountain ranges directed more or less north and south might arise in this manner, it is more difficult to imagine chains of mountains like the Himalayas or like the Pyrenees originating in the westto-east force arising from tidal or precessional effects. This brings us to the consideration of the possibility of the continents having shifted their relative positions during geological time.

Many are now weighing evidence for and against such extraordinary possibilities as to whether the Atlantic Ocean is not a comparatively recent innovation; whether New Zealand was not recently detached from Australia, and India from the eastern shores of Africa, and so on. Before this interesting question arose biologists and geologists generally got out of their difficulties by assuming the former existence of land connexions or "bridges" which subsequently "foundered" and disappeared.

Now, according to the present explanation of the surface movements of the earth, the foundering of such "bridges" would be difficult to realise; for they are of lower density than the basaltic magma upon which they at one time floated. So that it becomes very difficult to imagine the former existence of these bridges. Not only is this the case, but also the present theory certainly suggests that differential movements of the continents might quite possibly have taken place. I do not mean to convey that these supposed great movements necessarily arise out of our theory, but it is at least remarkable that a theory which appears to explain much-and on a basis which can claim to be more than merely hypothetical-should offer what may be regarded as a vera causa for continental drifting if other considerations require it. The continents during times of revolution become acted upon by forces tending to move them towards the east; and, what is even more relevant, these forces must of necessity be different in intensity from one continent to another. In fact, the magmatic drive applied to a continental mass depends upon the depth of its immersion and also on the existence of great displacements extending downwards into the deeper parts of the magma.

Another consideration in favour of continental drifting must be taken inio account. The continents become acted upon by these forces only during the period of magmatic fluidity. We saw that this fluidity is ultimately lost, mainly in consequence of heat escaping through the ocean floor ; this floor being probably more or less melted away during the process. It may be 
that the reduction in thickness of the ocean floor is carried so far as to remove what is really the main obstacle to differential continental movement--the existence of a strong and rigid ocean floor, holding the continents immovably fixed to one another.

We return for a moment to the problem of the elevation of such ranges as the Himalayas, which trend more or less east and west. We are now prepared for the possibility that the explanation of these events was due to a certain small amount of continental movement. It is a fact that tidal and precessional forces are greatest in equatorial regions. May it not have been that the great continent of Africa, experiencing the effects of this, rotated just a little, its southern extremity moving eastward; and so also for Peninsular India; so also for the Spanish Peninsula? A small turning movement, crushing the ancient geosynclines, would suffice. For, after all, the greatest mountains are but very tiny wrinkles upon the surface of this huge world.

The outflows of lava on the western coasts of the continents, or to the west of great mountain masses, or brought up by the downward faulting of rift valleys, to which I have already referred, seem to give us direct evidence of the magmatic pressures of which we have been speaking. The injection of lava inte the great mountains, or its ejection from lofty volcanoes, finds explanation in the great volumes of included basaltic magma which are taken up in the crushed and shattered sediments of the geosynclines when these are floated up from the depths of the earth's crust.

In the foregoing remarks I have endeavoured to trace, on the basis of isostasy and radio-activity, the existence of cyclical changes, prevailing in the isostatic layer, which are in harmony with the observed recurrent world-revolutions. While a certain grand simplicity in the nature of these events, and the existence of a general resemblance between the character of one revolution and that of the next, permit of this treatment, it would be an erroneous inference that the physical events of historical geology are concentrated in the relatively brief periods of world-wide mountain-building. For in truth an endless succession of minor changes have affected the crust of the earth. Between the great revolutions transgressions of the ocean have occurred over considerable areas. Crustal warping, and even mountain elevation of lesser ranges and batholithic invasion of the crust, as well as renewed volcanism, have not been uncommon. All the events of the greater revolutions may appear locally, and always on a lesser scale.

In point of fact, these lesser, inter-revolutionary events are, probably, part of the primary phenomenon and owe their existence to energy concerned with the genesis of the former. For consider that during millions of years the continental crust, throughout every part of it, has been subjected to those same enormous stresses, vertical and horizontal, that served to uplift the Cordilleras to heights of more than 20,000 feet; and that, at the time when the floor of the ocean congealed around the continents and tidal effects died out, the vast volume of the land was left deformed by these great stresses, strained, often to fracture wherever rigidity prevailed, and with isostatic adjustments profoundly disturbed.
The inter-revolutionary periods of geological history must witness the readjustments necessitated by this accumulation of potential energy. Areas of low resistance-i.e. the geosynclines, the volcanic areas, or recently deformed regions-must experience the concentrated results. Moreover, all the conditions for very prolonged continuance of these minor activities exist. For there is no other way in which the accumulated energy may find relief save in crustal disturbance or readjustment. It will be slowly doled out for ages as the effects of denudation call upon it, or as thermal events give it occasion to intervene, for the cooling of the magma beneath the continents must be extremely slow. Sheets of melted lava must underlie them, throughout almost the whole of geologica: time, although deeper down there may be comparative rigidity.

It will be apparent from all this that there is nothing unaccountable either in the existence or nature of inter-revolutionary events. On the contrary, we may say that their absence would be highly unaccountable. Even more, I think that as we study these events we must conclude that they cannot represent more than a fraction of the stored energy attending a great revolution.

This leads to the energy question at large. Whence does it all come? To answer fully that question would lead us back over much of the ground we have already pursued. But as regards energy other than radioactive we may briefly answer: "From the rotation of the earth." And is it not adequate? Look at the diagram of an earth-sector (Fig. 2) ; with a floating

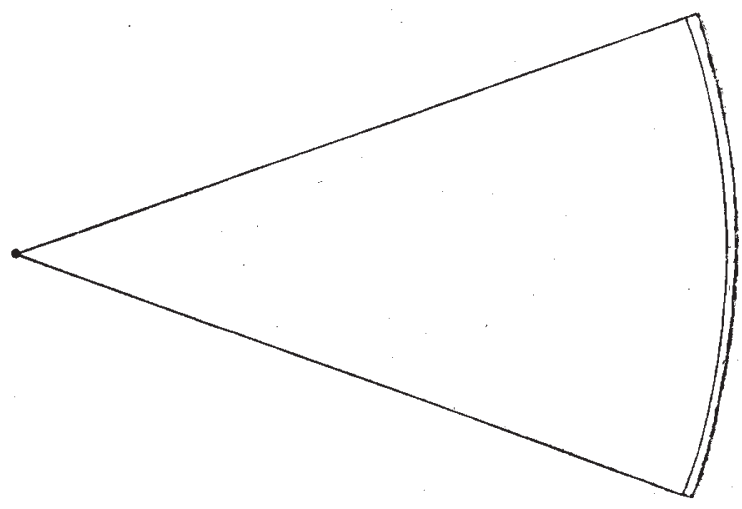

F.IG. 2.--Earth-sector showing basaltic layer and continents to scale of radius.

crust 20 miles thick and an isostatic layer 70 miles deep. Consider how petty are the crustal energies contrasted with the stored energy of the globe, built as it is out of materials twice as dense as the continental rocks, and possessed, even to-day, of a surface velocity of rooo miles an hour.

In its biological aspect how great and wonderful it all is! The living being working out his destiny on this poor raft, unknowing of the fiery ocean upon which his world is floating: unknowing of the inevitable sinking and uplifting which in truth largely control the destinies of his race. Death-dealing forces all around, and yet the light of life shining age after age upon the earth. 